\title{
O PERFIL DE TUTOR EAD ALMEJADO PELAS INSTITUIÇÕES PÚBLICAS DE ENSINO SUPERIOR BAIANAS
}

\author{
LAURO DE FREITAS/BA AGOSTO/2018
}

\author{
Emanuel do Rosário Santos Nonato - UNEB - enonato@uneb.br \\ Lorena Paim Moura - UNEB - Iorenapaim@hotmail.com \\ Braian Varjão Gama Bispo - IFBA - braiangama@gmail.com
}

Tipo: Investigação Científica (IC)

Natureza: Relatório Final de Pesquisa

Categoria: Estratégias e Políticas

Setor Educacional: EDUCAÇÃO SUPERIOR

\begin{abstract}
RESUMO
A educação a distância (EaD) exige um perfil profissional docente diferenciado e suas especificidades exigem a atuação de um conjunto de profissionais, de forma coletiva, distribuída e colaborativa. Dentre os profissionais da polidocência, o tutor virtual é o docente central, por ser o mediador pedagógico, responsável por promover a construção colaborativa e significativa do conhecimento. Motivado por conhecer as características almejadas nesse profissional, este artigo tem como objetivo identificar o perfil do tutor de cursos à distância buscado pelas Instituições Públicas de Ensino Superior (IPES) baianas. A compreensão deste fenômeno apontou para uma pesquisa documental, de abordagem qualitativa e de natureza exploratória.
\end{abstract}

Palavras-chave: Educação a Distância; Polidocência; Tutoria 


\section{INTRODUÇÃO}

O crescimento da oferta de cursos na modalidade de Educação a Distância (EaD) movimentou o mercado de trabalho dos profissionais de educação stricto sensu, em primeiro plano, e dos profissionais liberais que trabalham subsidiariamente na Área de Educação na formação inicial ou continuada de suas áreas profissionais. A função de tutor em cursos EaD entrou no rol de opções de trabalho na Educação.

Nesse universo, Instituições Públicas de Ensino Superior (IPES) e instituições privadas desenvolveram formas de contratação e perfis profissionais demandados que refletem as singularidades dessas instituições. Neste contexto, surge o interesse por entender qual o perfil de tutor para EaD almejado pelas IPES baianas. A partir deste problema de pesquisa, desenvolveu-se uma pesquisa documental a partir dos editais de seleção de tutores das IPES baianas para determinar, com base no requisitos e atribuições constantes nesses instrumentos, as características que são buscadas por essas instituições nos profissionais a serem contratados.

Tal movimento impôs, no campo teórico, uma compreensão da posição do tutor na arquitetura da docência em EaD. Partindo de Mill (2010) e Belloni (2006), este artigo discute a compreensão do trabalho docente na EaD para fundamentar o lugar do tutor nesse processo e subsidiar a análise do perfil que as IPES baianas vêm buscando nos tutores na atualidade.

\section{A POLIDOCÊNCIA NA EAD}

A educação a distância (EaD) definida por Moran como o processo de ensinoaprendizagem, mediado por tecnologias exige um perfil profissional docente diferenciado, promovendo uma transição do papel do professor de transmissor de conhecimento para mediador pedagógico.

O processo de ensino aprendizagem na educação a distância se dá através de ações desenvolvidas por vários atores. Ensinar em EaD implica um rearranjo da prática docente a partir da materialização de grupos de sujeitos que partilham aspectos da docência e colaboram para sua conformação. É nessa linha que Mill (2010) assume o conceito de polidocência com o qual quer dar conta desse todo complexo e dinâmico.

A complexidade organizacional e intensa dinâmica pedagógica da $\mathrm{EaD}$ evidencia a interdependência entre os membros da equipe e a fragmentação do processo de trabalho docente. Em um sistema de EaD todos os envolvidos no processo educativo 
são responsáveis pela aprendizagem. Para Mill (2010), surgem categorias profissionais redefinidas: como o docente-conteudista, o docente-tutor (virtual e presencial), 0 docente projetista educacional (ou designer instrucional ou estrategista pedagógico), entre outras.

Para Belloni (2006) é o uso intenso dos meios de comunicação e informação que torna o ensino mais complexo e exige segmentação, sendo esta a principal característica do ensino à distância. O rearranjo do trabalho docente na EaD é apresentado agrupado em três grandes grupos: o primeiro é responsável pela concepção e realização do curso e materiais; o segundo assegura o planejamento e organização da distribuição de materiais e da administração acadêmica (matrícula e avaliação); e o terceiro responsabiliza-se pelo acompanhamento do estudante durante o processo de aprendizagem (tutoria, aconselhamento e avaliação) (BELLONI, 2006, p. 84).

Contudo, não há um modelo único de educação à distância, como pontuam os Referenciais de Qualidade para Educação Superior a Distância (RQESD) (BRASIL, 2007, p. 19). Os programas podem apresentar diferentes desenhos e múltiplas combinações de linguagens e recursos educacionais e tecnológicos. Deixando claro que há flexibilidade quanto aos modos de organização. Este documento ressalta que, embora haja diversidade de modelos, com diferentes possibilidades de composição dos recursos humanos, "o ponto focal da educação superior é o desenvolvimento humano, em uma perspectiva de compromisso com a construção de uma sociedade socialmente justa”.

Define a equipe multidisciplinar em três categorias essenciais para uma oferta de qualidade: corpo docente, corpo de tutores, corpo técnico-administrativo. Ao classificar essas três categorias, o RQESD aparta os tutores da função docente e das funções administrativas. Ao descrever os Tutores, aprensenta-os como quadro diferenciado no interior das instituições, dada a sua importância no processo educacional de cursos superiores a distância: "o tutor deve ser compreendido como um dos sujeitos que participa ativamente da prática pedagógica" (BRASIL, 2007, p. 21).

A principal atribuição deste profissional é o esclarecimento de dúvidas através fóruns de discussão pela Internet, pelo telefone, participação em videoconferências, entre outros, de acordo com o projeto pedagógico. O tutor a distância tem também a responsabilidade de promover espaços de construção coletiva de conhecimento, selecionar material de apoio e sustentação teórica aos conteúdos e, freqüentemente, faz parte de suas atribuições participar dos processos avaliativos de ensino-aprendizagem, junto com os docentes (BRASIL, 2007, p. 21). 
A maioria das universidades públicas que oferecem $0 \mathrm{EaD}$ e tem convênio com 0 Sistema UAB adota as categorias propostas pelo Ministério da Educação para diferenciar os papéis docentes nos cursos de graduação a distância, assumindo que "o tutor deve ser compreendido como um dos sujeitos que participa ativamente da prática pedagógica. Suas atividades desenvolvidas a distância e/ou presencialmente devem contribuir para o desenvolvimento dos processos de ensino e de aprendizagem e para 0 acompanhamento e avaliação do projeto pedagógico" (BRASIL, 2007, p. 21).

Dentre os profissionais da polidocência, o tutor virtual é o docente central, por ser o mediador pedagógico, responsável por promover a construção colaborativa e significativa do conhecimento. Motivado por conhecer as características almejadas nesse profissional, este artigo tem como objetivo identificar o perfil do tutor de cursos à distância buscado pelas Instituições Públicas de Ensino Superior (IPES) baianas.

\section{SABERES DOCENTES}

O professor utiliza saberes disciplinares, curriculares, profissionais ou pedagógicos e experienciais para ensinar. Em especial na $\mathrm{EaD}$, os saberes tecnológicos integram um conjunto de saberes fundamentais para a prática docente. Belloni (2001) defende que a formação de professores, para o contexto presencial ou a distância, incorpore três dimensões: pedagógica, tecnológica, didática. E propõe a "formação de educadores capazes de realizar satisfatoriamente a integração aos processos educativos das novas e velhas tecnologias de informação e comunicação".

No contexto da educação a distância, o tutor é o docente mais exigido quanto aos saberes nas três dimensões, por seu caráter mediador do ensino-aprendizagem. $\mathrm{Na}$ perspectiva de Belloni (2006), destaca-se como papel do tutor, o despertar do caráter autônomo dos alunos. Para tanto é preciso perceber que as experiências dos alunos são fundamentais na construção do processo de ensino; participar das atividades como construtores e facilitadores; e ensinar aos alunos como aprender.

Embora muitos se esforcem em definir o papel e funções dos tutores, não há uma padronização para descrevê-los, favorecendo o surgimento de dúvidas. Desta forma, a definição das atribuições do tutor ficam à cargo da instituição e respectivo projeto pedagógico. Ressalta-se ainda, que esta função não possui descrição ou registro para o Ministério do Trabalho e que a ausência de políticas que regulamentem essa profissão afetam também a formação e capacitação de tutores. 
Os atos de gestão dos organismos do Estado deixam rastros e tornam sua ação teleológica reconstituível. Neste sentido, a intenção de buscar a identificação do perfil dos tutores buscado pelas IPES baianas apontou para a pesquisa documental, de abordagem qualitativa, de natureza exploratória, como a metodologia mais adequada para empreender o fenômeno em comento.

Nesse sentido, Ludke e André (1986, p. 38) pontuam a análise documental como o caminho para se "identificar informações factuais nos documentos a partir de questões ou hipóteses de interesse". Por seu turno, Cellard (2008, p. 285) acentua a condição da Pesquisa Documental de, não raro, "único testemunho de atividades particulares ocorridas num passado recente".

Não obstante a compreensão ampla que se tem de documento (LÜDKE, 1986; CELLARD, 2008), os documentos analisados neste estudo são os editais públicos lançados pelas IPES através da imprensa oficial. Isto garante per se a autenticidade da informação documental (CELLARD, 2008).

O estudo foi desenvolvido em etapas consecutivas mediante pesquisa bibliográfica para fundamentação das categorias de análise do fenômeno; pesquisa documental exploratória para levantar e constituir o corpus da pesquisa, conforme quadro a seguir; análise documental preliminar do corpus determinado para identificar os elementos indicadores de aderência do documento ao problema de pesquisa e estabelecimento das Unidades de Análise (LÜDKE, 1986) e análise do documento, à luz do referencial teórico construído, para reconstituir o perfil do tutor idealizado pelas IPES baianas.

\begin{tabular}{|l|l|l|}
\hline Instituição Pública de Ensino Superior (IPES) & Edital & Ano \\
\hline Universidade Federal da Bahia (UFBA) & № 11 & 2017 \\
\hline Instituto Federal de Educação, Ciência e Tecnologia (IFBA) & NNo 5 & 2017 \\
\hline Universidade do Estado da Bahia (UNEB) & № 019 & 2018 \\
\hline Universidade Estadual do Sudoeste da Bahia (UESB) & № 176 & 2017 \\
\hline Universidade Federal do Recôncavo da Bahia (UFRB) & № 004 & 2018 \\
\hline Universidade Estadual de Santa Cruz (UESC) & № 104 & 2017 \\
\hline Universidade Federal do Vale do São Francisco (UNIVASF) & № 6 & 2017 \\
\hline
\end{tabular}

Tabela 1: Editais que compõem o corpus analisado neste estudo

Para a formação do corpus, foram consideradas sete IPES baianas, todos eles referentes à seleção de profissionais para atuarem nos cargos de Tutor Online ou Tutor 
Presencial, que foram obrigatoriamente publicados nos anos de 2017 ou 2018, conforme disposto na Tabela 1. Ressalta-se que foi considerado apenas um edital por instituição observada, pois observou-se que os editais publicados pelas mesmas no período observado são similares entre si. A partir desse corpus, a análise documental permitirá, pelo confronto da carga horária, remuneração, requisitos obrigatórios e atribuições indicadas no instrumento, construir o perfil buscado pelas IPES baianas para o tutor.

\section{ANÁLISE DE DADOS}

Consoante o problema de pesquisa apresentado, a análise dos editais indicados na Tabela 1 se centrou na construção de um perfil do tutor almejado pelas IPES baianas. Para tanto, o primeiro passo foi contrastar os dados referentes às categorias a serem analisadas (carga horária, remuneração, requisitos obrigatórios e atribuições indicadas).

Conforme a RQESD, não existe um modelo único para a EaD. No entanto, um dado que ilumina a análise é o fato de que todas as IPES cujos editais foram analisados são vinculadas ao Sistema Universidade Aberta do Brasil (UAB). Desta forma, em todos eles, os candidatos são selecionados para atuar como bolsistas no cargo de Tutor do Sistema UAB, com carga horária de 20 horas semanais, fazendo jus à remuneração de $\mathrm{R} \$ 765,00$, conforme estabelecido pela Coordenação de Aperfeiçoamento de Pessoal de Nível Superior (CAPES) na Portaria CAPES no 183 de 21 de outubro de 2016.

Nesse sentido, a uniformidade de remuneração e de carga horária de trabalho está vinculada conceitualmente, não à descrição das funções ou à configuração das atividades a serem desenvolvidas, mas ao modelo de fomento externo a que essas IPES se submetem e aos condicionamentos que esse modelo de fomento impõe.

Nenhum dos editais menciona qualquer tipo de auxílio financeiro ou benefício qualquer além do valor da bolsa, como auxílio transporte ou alimentação, exceto nos editais que exigem disponibilidade para viagens, onde é previsto o custeio de diárias e passagens pelas universidades. Frisa-se também que, em todos os editais, é esclarecido que a contratação dos tutores não gera vínculo empregatício com as IPES, consoante a política de pagamento por bolsas da CAPES. Já aqui um ponto central se manifesta na uniformidade da remuneração e condições trabalhistas.

Alguns editais exigem ou preferem servidores públicos, o que evidencia nestes casos que o tutor já deve dispor de outra atividade principal remunerada. Este fato, aliado ao valor da remuneração e a impossibilidade de acúmulo de bolsas expõe o cargo de tutor como atividade de renda complementar ou extra. 
A variável requisitos para o cargo de tutor online está descrita nos editais analisados, conforme tabela a seguir.

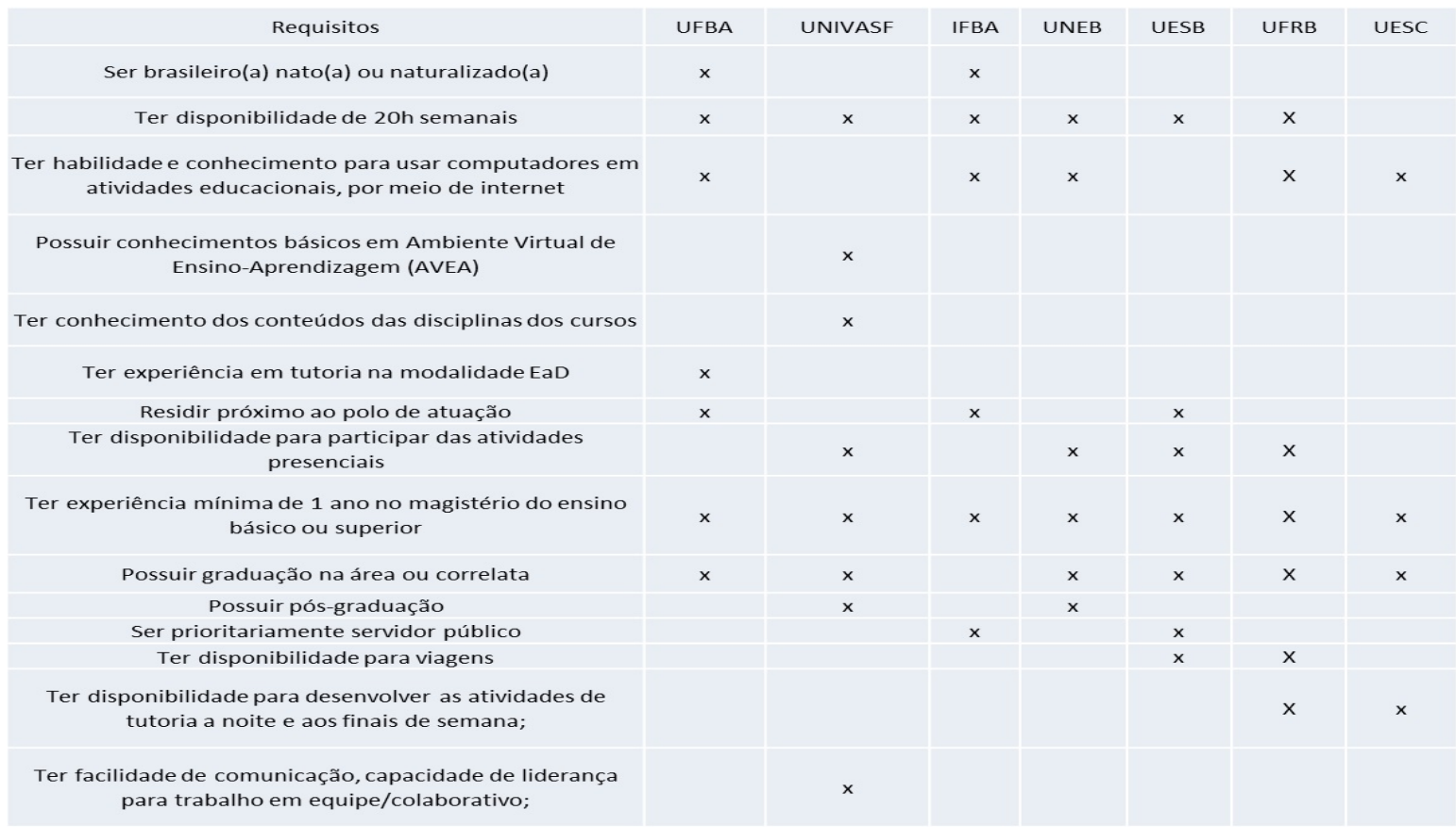

Tabela 2: Requisitos obrigatórios definidos pelas IPES analisadas para o cargo de tutor online

Considerando as três dimensões de formação docente defendida por Belloni observa-se no tabela 2 que os editais versam com maior ênfase sobre os saberes tecnológicos, seguidos pelos saberes pedagógicos e em detrimento dos saberes didáticos. Como competência tecnológica é exigida habilidade de acesso à computadores e internet, utilização de e-mail, fóruns e chat. O conhecimento específico de Ambiente Virtual de Ensino e Aprendizagem (AVEA) é citado por apenas uma instituição. Para comprovar a competência pedagógica, é solicitado experiência em magistério e graduação. Apenas uma IPES exige conhecimento em tutoria EaD e também uma, conhecimento específico relacionado ao conteúdo da disciplina. Saberes didáticos podem ficar subentendidos em algumas dessas exigências, porém não especificados.

Em relação aos requisitos obrigatórios determinados nos editais, percebe-se uma congruência entre a maioria dos editais analisados nos seguintes critérios: 1) disponibilidade de 20 horas semanais; 2) possuir acesso e habilidade no uso de computadores e Internet, e principalmente, com as ferramentas inerentes ao trabalho de tutoria que utilizam estes meios, como e-mail, AVA, fóruns e chat; 3) residir próximo ao polo onde irá atuar (ressalta-se que o critério de proximidade varia entre os editais); 4) disponibilidade para participar de atividades presenciais durante a semana; 5) possuir grau de formação acadêmica igual ou superior aos cursos nos quais irão atuar; sendo 
que apenas a UNIVASF e a UNEB exigem pós-graduação; 6) possuir experiência comprovada de no mínimo um ano no magistério do ensino básico ou superior, excetuando a UFBA que exige apenas 6 meses de experiência profissional, entretanto também exige experiência específica em tutoria na modalidade EaD; 7) ter disponibilidade para viajar, incluindo finais de semana, para realizar atividades presenciais como aplicação de avaliações em diferentes polos; 8) não receber nenhuma bolsa deste ou de outros programas de fomento a estudo e pesquisa do Governo Federal.

No que tange às atribuições dos tutores nessas instituições (Tabela 3), observa-se em primeiro plano que as IPES baianas, com exceção da UFBA, consideram como principal atribuição do tutor, a mediação da comunicação de conteúdos entre o professor e os cursistas. A mediação da comunicação de conteúdo limita o tutor à condição de transmissor das mensagens emitidas pelo professor, sem autonomia para escolher métodos e estratégias que promovam a construção significativa de conhecimento. Nesse sentido, essa visão restritiva do tutor contrapõe-se à RQESD que apresenta como responsabilidades do tutor promover espaços de construção coletiva de conhecimento e selecionar material de apoio e sustentação teórica aos conteúdos.

Atribuições

Mediar o processo de aprendizagem

Mediar a comunicação de conteúdos entre o Professor e os Cursistas

Participar de reuniões presenciais

Participar das atividades de capacitação e atualização promovidas pela universidade

Apoiar o professor da disciplina no

desenvolvimento das atividades docentes

Estabelecer contato permanente com os alunos e mediar as atividades discentes

Participar do processo de avaliação da disciplina sob a orientação do professor responsável

Atender aos prazos determinado

Elaborar relatórios mensais de acompanhamento dos alunos e encaminhar à coordenação de tutoria Manter regularidade de acesso ao ambiente virtual de aprendizagem (AVA) e dar retorno às solicitações do cursista no prazo máximo de 24 horas

Apoiar operacionalmente a coordenação do curso nas atividades presenciais nos polos, em especial na aplicação de avaliações.
UFBA UNIVASF IFBA UNEB UESB UFRB UESC $\mathrm{X}$

\begin{tabular}{ll|lll}
$\mathrm{X}$ & $\mathrm{X}$ & $\mathrm{X}$ & $\mathrm{X}$ & $\mathrm{X}$
\end{tabular}

$\mathrm{X}$ $\mathrm{X}$

X $\quad$ X

\begin{tabular}{ll|lll} 
X & X & X & X & X
\end{tabular}

\begin{tabular}{l|llll} 
X & $\mathrm{X}$ & $\mathrm{X}$ & $\mathrm{X}$ & $\mathrm{X}$
\end{tabular}

\begin{tabular}{ll|lll} 
X & $\mathrm{X}$ & $\mathrm{X}$ & $\mathrm{X}$ & $\mathrm{X}$
\end{tabular}

X $\quad$ X

$\begin{array}{lllllll}\text { X } & \mathrm{X} & \mathrm{X} & \mathrm{X} & \mathrm{X} & \mathrm{X}\end{array}$

$\begin{array}{llllllll}X & X & X & X & X & X & X\end{array}$

\begin{tabular}{l|lll} 
X & X & X & X
\end{tabular}

Tabela 3: Principais atribuições dos tutores online descritas nos editais das IPES baianas 
Observou-se ainda que, dentre as sete analisadas, cinco (IFBA, UESB, UFRB, UESC e UNIFASV) seguem basicamente o disposto no Anexo VII da Portaria CAPES no 183 de 21 de outubro de 2016, o qual elenca uma lista genérica de funções que devem ser atribuídas ao Tutor do Sistema UAB. As únicas variações identificadas neste quesito entre os editais dessas universidades foram: (1) $O$ edital do IFBA não atribui ao Tutor Online a função de "apoiar operacionalmente a coordenação do curso nas atividades presenciais nos polos, em especial na aplicação de avaliações", em razão do instituto imputar tal função ao cargo de Tutor Presencial, conforme especificado no mesmo edital; (2) Os editais da UNEB e UNIFASV exigem que os tutores participem de atividades de capacitação e atualização promovidas por suas Secretarias de Educação à Distância.

Ainda sobre as atribuições dos tutores indicadas nos editais analisados, notou-se que a UNEB elenca uma lista reduzida de funções. Ao não considerar necessário construir um perfil de tutor no processo de seleção, a IPES aponta para a naturalização de uma concepção prévia de tutoria. salienta-se que, o edital da UFBA foi o único a especificar a lista de atribuições dos cargos de tutor de forma não genérica, para além da tabela 3 , atendendo à todas as atribuições especificadas pela CAPES por meio da portaria supracitada, porém deixando claro de que forma e com quem cada uma delas deve ser desempenhada.

Isto posto, a análise apontou que os tutores buscados nos editais supracitados têm como principais atribuições: mediar a comunicação entre professores e cursistas; desenvolver atividades de apoio ao professor; acompanhamento das atividades discentes e apoio às avaliações. Sendo pré-requisitos conhecimentos básicos de informática; experiência mínima em docência, podendo esta ser presencial ou EaD; e titulação mínima equivalente ao curso pretendido.

\section{CONCLUSÃO}

No modelo da UAB reproduzido pelas IPES, o tutor não é reconhecido como docente, embora dele se exija como requisito experiência em magistério da Educação Básica ou Superior, noções tecnológicas básicas e restrita qualificação. De forma geral, não obstante a evidente contradição, não exigem experiência ou qualificação específica em EaD, embora pressuponham formação continuada.

Contudo, o estudo que apresentamos deixa clara a força condutora do modelo de fomento como condicionador da concepção de $\mathrm{EaD}$, em sentido amplo, e de tutoria em sentido restrito. Os editais analisados demonstram que o perfil de tutor requerido não 
leva em conta as especificidades das IPES ou dos cursos, mas buscam enquadrar o tutor no perfil de bolsista definido pelo projeto de fomento: o Sistema UAB. Neste sentido, dificilmente se poderá falar de perfil de tutor construído pelas IPES, mas daquele definido pela UAB. Isto, aponta para a necessidade de amadurecimento teóricometodológico da EaD em cada IPES

\section{REFERÊNCIAS}

BELLONI, M. L. Educação a Distância. São Paulo: Autores Associados, 2006.

BRASIL. Coordenação de Aperfeiçoamento de Pessoal de Nível Superior. Regulamenta as diretrizes para concessão e pagamento de bolsas aos participantes da preparação e execução dos cursos e programas de formação superior, inicial e continuada no âmbito do Sistema Universidade Aberta do Brasil. Portaria no 183 de 21 de outubro de 2016.

BRASIL. Ministério da Educação. Secretaria de Educação a Distância. Referenciais de Qualidade para a Educação Superior a Distância. Agosto de 2007. Disponível em http://portal.mec.gov.br/seed/arquivos/pdf/legislacao/refead1.pdf acesso em 29/04/2018.

CELLARD, A. A análise documental. In: POUPART, J. et al. A pesquisa qualitativa: enfoques epistemológicos e metodológicos. Petrópolis, Vozes, 2008.

LÜDKE, M.; ANDRÉ, M. E.D.A. Pesquisa em Educação: abordagens qualitativas. São Paulo: EPU, 1986.

MILL, D.; OLIVEIRA, M. R. G.; RIBEIRO, L. R. C. Múltiplos enfoques sobre a polidocência na Educação a Distância virtual. In: MILL, D.; OLIVEIRA, M. R. G.; RIBEIRO, L. R. C. Polidocência na educação a distância: múltiplos enfoques. São Paulo: EdUFSCar, 2010, p. 13-22.

MORAN, J. M. Novos caminhos do ensino à distância. Informe CEAD - Centro de Educação à Distância, SENAI, 1 (5), p. 1-3, 1994. 